\title{
The functional role and diversity of soil nematodes are stronger at high elevation in the lesser Himalayan Mountain ranges
}

\author{
Yasmeen Kouser $^{1}$ | Ali Asghar Shah ${ }^{1}$ | Sergio Rasmann² (D)
}

${ }^{1}$ Department of Zoology, Nematode Biodiversity and Genomics Research Lab, Baba Ghulam Shah Badshah University, Rajouri, India

${ }^{2}$ Laboratory of Functional Ecology, Institute of Biology, University of Neuchâtel,

Neuchâtel, Switzerland

\section{Correspondence}

Ali Asghar Shah, Department of Zoology, Nematode Biodiversity and Genomics Research Lab, Baba Ghulam Shah Badshah University, Rajouri 185234, J\&K, UT, India.

Email: aashah@bgsbu.ac.in

Sergio Rasmann, Laboratory of Functional Ecology, Institute of Biology, University of Neuchâtel, Rue Emile-Argand 11, 2000 Neuchâtel, Switzerland.

Email: sergio.rasmann@unine.ch

Funding information

Council of Scientific and Industrial Research, India, Grant/Award Number: 09/1172(0002)/EMR-2018; Schweizerischer Nationalfonds zur Förderung der Wissenschaftlichen Forschung, Grant/ Award Number: 31003A_159869

\begin{abstract}
Soil nematodes are a foremost component of terrestrial biodiversity; they display a whole gamut of trophic guilds and life strategies, and by their activity, affect major ecosystem process, such as organic matter degradation and carbon cycling. Based on nematodes' functional types, nematode community indices have been developed, and can be used to link variation in nematodes community composition and ecosystem processes. Yet, the use of these indices has been mainly restricted to anthropogenic stresses. In this study, we propose to expand the use of nematodes' derived ecological indices to link soil and climate properties with soil food webs, and ecosystem processes that all vary along steep elevation gradients. For this purpose, we explored how elevation affects the trophic and functional diversity of nematode communities sampled every $300 \mathrm{~m}$, from about $1,000 \mathrm{~m}$ to 3,700 $\mathrm{m}$ above sea level, across four transects in the lesser Himalayan range of Jammu and Kashmir. We found that (a) the trophic and functional diversity of nematodes increases with elevation; (b) differences in nematodes communities generate habitat-specific functional diversity; (c) the maturity index $(\Sigma \mathrm{MI})$ increases with elevation, while the enrichment index decreases, indicating less mature and less productive ecosystems, enhanced fungalbased energy flow, and a predominant role of nematodes in generating carbon influxes at high-elevation sites. We thus confirm that the functional contribution of soil nematodes to belowground ecosystem processes, including carbon and energy flow, is stronger at high elevation. Overall, this study highlights the central importance of nematodes in sustaining soil ecosystems and brings insights into their functional role, particularly in alpine and arctic soils.
\end{abstract}

\section{KEYWORDS}

Alpine environment, elevation gradient, function trophic structure, metabolic footprint, soil biodiversity, soil ecology 


\section{1 | INTRODUCTION}

It has been estimated that soils of terrestrial ecosystems sustain about $25 \%$ of the world biodiversity (Bach et al., 2020; Decaëns, 2008; Decaëns et al., 2006); consequently, soils function as biodiversity reservoirs, and have the potential to mainly contribute to ecosystem functioning (Bardgett \& van der Putten, 2014; Decaëns, 2010; Fitter et al., 2005). Indeed, soil fauna functional diversity has been shown to contribute to ecosystem functioning by impacting on different processes, such as primary production and nutrient cycling of carbon, phosphorous, or nitrogen (Brussaard, 1997), the decomposition of organic matter, or the assimilation of carbon in food webs, which in turn regulates energy movements between the below and the aboveground compartments of the ecosystems (Hunt \& Wall, 2002; Krumins et al., 2013).

The group of roundworms (i.e., the nematodes; phylum Nematoda) represents a major component of the belowground fauna diversity. Nematodes include more than 27,000 described species (Hodda, 2011; Hugot et al., 2001), are found almost in every inhabitable place on Earth, and represent about $80 \%$ of belowground bulk metazoan taxonomic and functional diversity (Bongers \& Bongers, 1998; Hodda et al., 2009). Nematodes can be assigned to practically all existing trophic groups, including the herbivore, fungivore, bacterivore, predator, unicellular eukaryote feeder, parasite, and omnivore trophic and functional group (Yeates et al., 1993). Nematodes can also be functionally assigned to a wide gamut of ecological adaptations, ranging from being classified as "colonizer" (i.e., r strategists,) to being classified as "persister" (i.e., K strategists), and all in between, such as along the colonizer-persister ("cp") scale as described by Bongers (1990). Nematodes therefore constitute a key component of the soil microbiota, and contribute to regulating several ecosystem processes, such as mineral cycling, succession processes, and energy flow (Andrén et al., 1995; Bongers \& Bongers, 1998; Boström \& Sohlenius, 1986).

Numerous studies have demonstrated the critical role of climate in the development and maintenance of soil nematode diversity (Chen et al., 2015; Nielsen et al., 2014; Song et al., 2017). For instance, Nielsen et al. (2014) showed that nematode community composition was strongly related to two main climatic factors, mean annual rainfall and temperature, which accounted for $65 \%$ and $58 \%$ of the total variation in community differences, respectively. Similarly, mean annual precipitation has been shown to influence nematode assemblage at the regional scale (Chen et al., 2015). In addition, climate can directly impact on local soil and vegetation characteristics (Rodriguez-Iturbe et al., 1999), and thus climate, indirectly, can influence soil invertebrate communities via changes in vegetation and soil properties (Kergunteuil, 2016). Therefore, contemporary and historical climatic factors can be used to study changes in species and functional diversity of soil nematodes across large geographic scales (Li et al., 2020).

In addition to climate, it is well established that soil nematode diversity, abundance, and composition are also influenced by soil physicochemical properties, such as soil temperature (de Ruiter et al., 1998), relative humidity (Dinoor \& Eshed, 2003), organic matter content (Collins et al., 1995; Cook et al., 1992; Crawford et al., 2005; De Deyn et al., 2003, 2004), phosphorus (De La Peña et al., 2006), texture, or salinity (Djigal et al., 2004), either from the local to the large scales (Chen et al., 2015; Liu et al., 2016; Quist et al., 2019; van den Hoogen et al., 2019). As a consequence, the study of the taxonomic and functional structure of nematode communities can, in turn, be used for assessing soil quality (Brinkman et al., 2008; Sochová et al., 2006; Wilson \& Kakouli-Duarte, 2009), as well as for evaluating natural changes in soil ecological conditions, for instance, along large-scale ecological and climatic gradients (Kergunteuil, 2016). Accordingly, several indices have been developed that summarize the functional role and the contribution of nematodes in the ecosystem (Bongers \& Ferris, 1999; Ferris, 2010; Ferris et al., 2001). For instance, the "Channel index," the "Enrichment index," and the "Structure index," which are all derived from calculating the weighted functional diversity components of the soil nematodes communities (Berkelmans et al., 2003; Ferris et al., 2001), represent the predominant decomposition pathways, food web response to available resources and state of food web affected by environmental stress, respectively (Ferris \& Bongers, 2009; Ferris et al., 2001) Moreover, the "Metabolic Footprint," which quantifies the amplitude of $C$ utilization by different components of the nematode soil food web, can function as an indicator of carbon and energy flow in the soil (Ferris, 2010). Being integrators of ecosystems properties, we therefore expect these indices to vary across habitat types, as well as local climatic and edaphic conditions.

While studies relating nematodes' functional structure and soil functioning remain mostly restricted to anthropogenic systems (Freckman \& Ettema, 1993; Šalamún et al., 2014; Zhao et al., 2015), studying functional variation of soil nematode communities in natural systems can inform on the potential natural relationship between belowground diversity, ecosystem function, soil properties, and climate (van den Hoogen et al., 2019). In this context, we here propose to expand the use of nematodes' derived ecological indices to study natural populations' variation along large-scale ecological gradients, which in turn, will allow increasing our understanding of how soil nematodes contribute and inform on the changes in ecosystem functioning across contrasted landscapes (Ritz \& Trudgill, 1999; Wilschut et al., 2019; Yeates, 2003). In this regard, studying nematode communities' functional variation along steep elevation gradients can be used to dissect the link between climate and soil conditions and nematode functional properties within a homogenous biogeographical and evolutionary background (Kergunteuil, 2016; Körner, 2007).

The purpose of this study was thus to investigate whether along elevation gradients, nematode communities and functionalities vary predictably with soil and climatic properties. For this, we studied soil community's composition along four elevation transects of Northern India (Jammu and Kashmir region). Based on previous studies along elevation gradients in the Alps (Kergunteuil, 2016), we hypothesized that (a) nematodes' functional composition varies with elevation, (b) nematodes' functional beta-diversity covary with changes in soil and climatic conditions along the elevational gradient, 
and (c) indices related to ecosystem properties also vary with nematode communities being more associated with more productive and mature ecosystems at low versus high elevation. Interestingly, it was previously shown that along the Alpine elevation gradients, several soil nematodes' trophic and functional groups, such as the herbivores, increase with elevation (Kergunteuil, 2016). These findings were to some extent in opposition to classic hypotheses of biodiversity changes along elevation, in which, for most clades, theory predicts a decline in biodiversity with elevation, indeed due to an increase of more constrained and stressful environmental conditions at high elevation. By studying similar ecosystem dynamics but in an entirely different setting-the Himalayas versus the Alps-we ultimately hope to draw broader conclusions about soil nematodes' biodiversity patterns and soil functioning in nature.

\section{2 | MATERIALS AND METHODS}

\section{1 | Study area}

We surveyed soil nematode communities along the Pir Panjal mountain range, a group of mountains in the Lesser Himalayan region, running from east-southeast to west-northwest, and including the Indian Territory of Jammu and Kashmir, where this study was conducted, and where the average elevation varies from 1,000 $\mathrm{m}$ above sea level (a.s.l.) to $4,000 \mathrm{~m}$ a.s.I. Within this region, four elevation transects were selected viz., Darhal, Thanamandi, Budhal, and Bakori transects (Figure 1, Table S1). The transects span elevations ranging as low as about 1,000 $\mathrm{m}$ a.s.l., which are characterized by evergreen forests dominated by arboreal plant species, such as Quercus leucotricophora, Pinus wallichiana, Pyrus pashia, Rhododendron arboreum, and Priensepia utilis, and to almost 3,700 $\mathrm{m}$ a.s.l., habitats which are characterized by alpine meadows and recent glacial retreats (Table $\mathrm{S} 1$ ).

\subsection{Extraction of climatic variables}

To characterize the climatic conditions present at each site along the elevational transects, we extracted the 19 BIOCLIM variables from the Chelsa global climate dataset (https://chelsa-climate.org/biocl $\mathrm{im} /$ ) at 30-s resolution (Karger et al., 2017). For statistical analyses, we removed overly correlated variables from the full list using the package caret (Kuhn et al., 2020), and ended up with 10 variables describing the climatic niche of each site (Table S2).

\section{3 | Soil and nematode sampling}

Nematodes were sampled between June and October 2020 across the four transects, and starting end of June at the lowest sites, and finishing in October at the highest elevation sites. Within each transect, we sampled 10 sites, separated from one another about 300 m

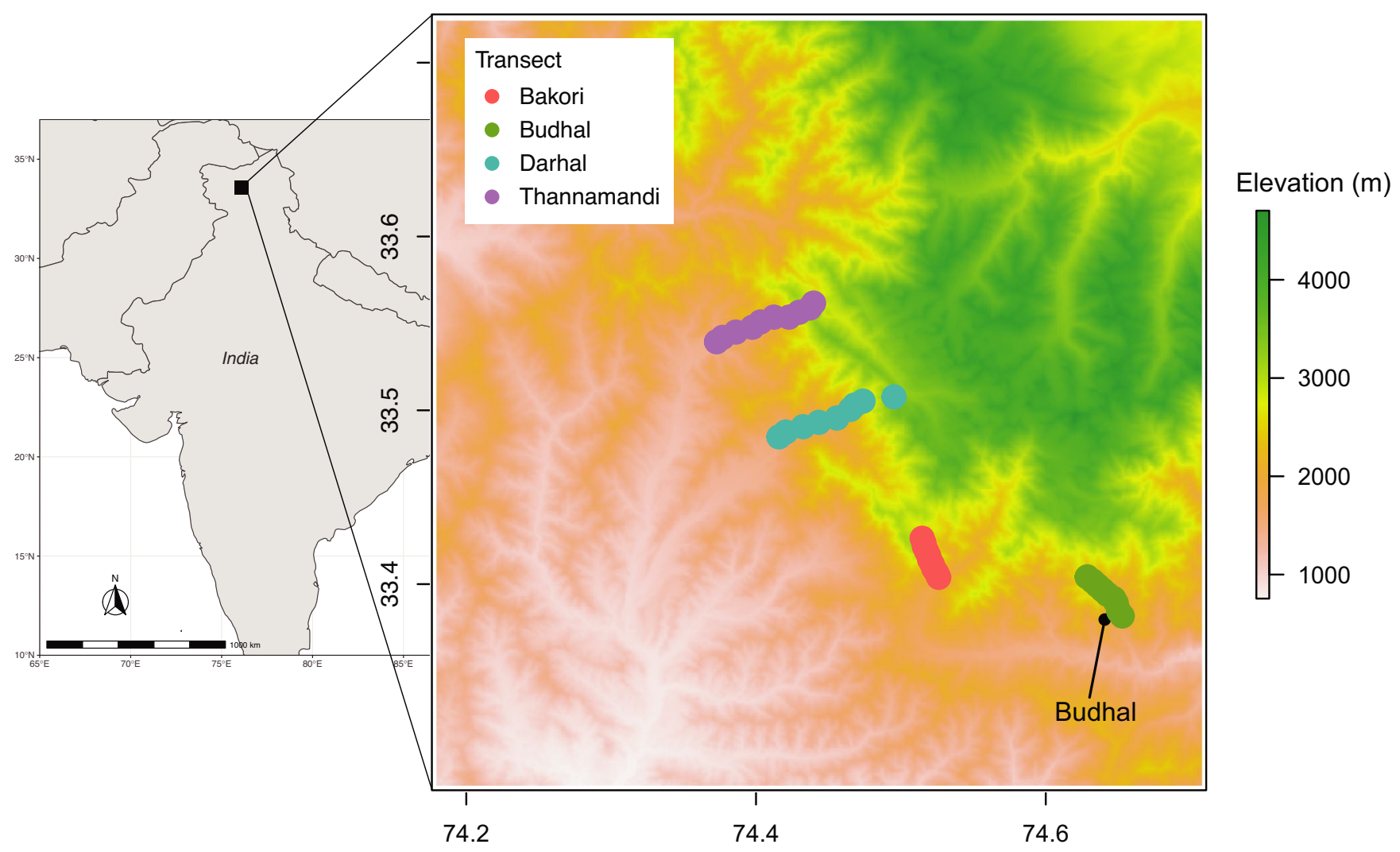

FIGURE 1 Sampling sites along elevation gradients. Shown is an elevation map of the Indian Jammu and Kashmir region in which four elevation transects were chosen for sampling nematode biodiversity 
in elevational distance so as to yield a total of 40 sites (Table S1). At each site, a sampling quadrat of $2 \times 2 \mathrm{~m}$ was randomly chosen within characteristic and homogenous vegetation type of the site. In sub-alpine areas, soil samples were predominantly collected within Fagus sylvatica, Abies pindrow, Pinus spp., Quercus spp., or Castanea sativa-dominated forests, whereas sampling in the alpine elevation stage was performed in alpine grasslands found above the timberline. Everywhere, agricultural or urban lands were avoided. At each site, about $10-12$ soil cores of $10 \mathrm{~cm}$ diameter and $10-20 \mathrm{~cm}$ deep were collected until reaching a sufficient amount of soil (about $1 \mathrm{~kg}$ fresh weight) after the removal of big (>2 cm in diameter) rock particles. Soil samples were then placed in a cold room $\left(4^{\circ} \mathrm{C}\right)$ within $24 \mathrm{hr}$ after sampling; between one and four days later, from this well-homogenized bulk soil material, a subsample of $100 \mathrm{~g}$ of fresh soil was used for extracting soil nematodes using the sieving and Baermann funnel method (Barker, 1985). The Baermann funnel method has been amply used for sampling nematodes across a wide variety of habitats and substrates, including soils and plant tissues (e.g., Freckman \& Virginia, 1989; Kergunteuil, 2016; Son \& Moon, 2013; Viglierchio \& Schmitt, 1983).

All nematodes in each sample were then counted under an Olympus Stereo-zoom SZX16 microscope, mounted into slides for identification to the genus level, and assigned to various functional guilds based on their trophic group and life history strategies (Yeates et al., 1993) (Table S3). Next, another subsample of the bulk soil was used for measuring soil parameters, including soil humidity, $\mathrm{pH}$, conductivity, and temperature. For soil humidity, we calculated the difference between soil fresh weight and soil dry weight after 7 days at $70^{\circ} \mathrm{C} ; \mathrm{pH}$ and conductivity were measured using a $\mathrm{pH}$ meter/ Conductometer (HANNA HI-98129 pH, EC and TDS Meter, HANNA Instruments AG, Langnau bei Reiden, Switzerland), after mixing $50 \mathrm{~g}$ of this subsample with $100 \mathrm{ml}$ of deionized water. Soil temperature was measured on site with a soil thermometer.

\subsection{Nematode communities' functional characterization}

Depending upon the abundance of functional guilds of nematodes, various indices were calculated so as to analyze the functional role of nematode-based food webs along various mountain transects (Bongers \& Bongers, 1998; Ferris et al., 2001). In order to do so, all identified nematodes were classified into five main trophic habits (bacterial-feeders, fungal feeders, plant-feeders, omnivores, and predators (Yeates et al., 1993)), and along the colonizer-persister (cp) scale (Bongers, 1990) (Table S3). Because we were working in yet largely unexplored territory (Northern India) in terms of nematode functional characterization, we resolved to only work with two major indices of relating nematodes' functional groups to ecosystem functioning: (a) the Sigma maturity index ( $\Sigma \mathrm{MI}$; Bongers, 1990), representing the proportions of the different $\mathrm{cp}$ groups for the whole nematode community, where higher values indicate that nematodes harboring "persister" life history traits are predominant within each of those different nematode categories. (b) The Enrichment index (EI; Ferris et al., 2001), which is based on the biomass of opportunistic nematodes that respond rapidly to the increase in bacterial and fungal populations that arise from organic matter decomposition. High values indicate high soil enrichment and high fertility. Biomass values were extrapolated from the NINJA (https://sieriebriennikov. shinyapps.io/ninja/).

\section{5 | Statistical analyses}

All statistical analyses were performed using R software, version 4.0.3 (R Development Core Team, 2020).

1. Soil-climate covariation: First, the effect of elevation on all individual soil and climate variables was tested using a mixed linear model (package Ime4 (Bates et al., 2015)) with "elevation" as fixed factor and "transect" as random factor. Second, we tested for a shared structure between soil properties and climatic conditions, which would represent a coupled soil-climate syndrome along elevation gradients, using a coinertia analysis. In other words, here we tested whether the matrices of soil parameters and climatic variables concomitantly vary across different sites. If this is the case, it would lead us to conclude that sites covary in their soil and climatic properties. The coinertia analyses were performed using the ade4 package (Dray et al., 2003; Dray \& Dufour, 2007), and the significance of the shared variance was assessed using a Monte Carlo test as implemented in ade4. When the coinertia analysis was significant (i.e., there is a significant soil/climate structuration across sites; see Figure S1), we performed a linear regression between combined soil-climate syndrome (coinertia 1) and elevation using a mixed linear model (package Ime4 (Bates et al., 2015)) with "elevation" as fixed factor and "transect" as random factor.

2. Nematodes trophic diversity covary with changes in soil and climatic conditions along the elevational gradient. First we assessed the effect of the coupled soil/climatic variables on the six major trophic groups of nematodes (herbivores, fungivores, bacterivores, predators, omnivores, and parasites) using a mixed linear model (package Ime4) with "coinertia axis 1" as fixed factor and "transect" as random factor. Second, we scored the effect of individual soil and climatic variables on the different trophic groups by performing a distance-based redundancy analysis (dbRDA) between nematode communities and (a) the climatic variable matrix and (b) the soil variable matrix. Distance matrices were built using Bray-Curtis dissimilarity values, and significances were tested using permutational analyses of variance function capscale, the package vegan (Oksanen et al., 2013).

3. Nematode functional indices change along elevation. We assessed the effect of the coupled soil/climatic variables on the two nematode functional indices ( $\Sigma \mathrm{MI}$ and $\mathrm{El}$ ) using a mixed linear model (package Ime4) with "coinertia axis 1" as fixed factor and "transect" as random factor (Table 1). 
TAB LE 1 Type III Analysis of Variance Table with Satterthwaite's method for measuring the effect of the combined soil/climate variation (coinertia axis 1 , Figure S1) on the different nematode trophic guilds

\begin{tabular}{llllrrr} 
& SQ & NumDF & DenDF & \multicolumn{1}{c}{$\boldsymbol{F}$} & $\operatorname{Pr}(>F)$ & \\
\hline Herbivores & $2,646.7$ & 1 & 35.67 & 49.17 & $<0.001$ & $* * *$ \\
\hline Fungivores & 221.8 & 1 & 37.77 & 20.93 & $<0.001$ & ${ }^{* * *}$ \\
\hline Bacterivores & 29,906 & 1 & 35.54 & 129.46 & $<0.001$ & $* * *$ \\
\hline Predators & 72.663 & 1 & 38 & 1.79 & 0.187 & \\
\hline Omnivores & 13,012 & 1 & 35.67 & 84.63 & $<0.001$ & $* * *$ \\
\hline Parasites & $2,650.3$ & 1 & 20.71 & 6.43 & 0.019 & $*$ \\
\hline
\end{tabular}

Note: Signif. codes: $0^{(* * *)} 0.001^{(* *)} 0.01^{(*)} 0.05$ '. $0.1^{\prime \prime} 1$.

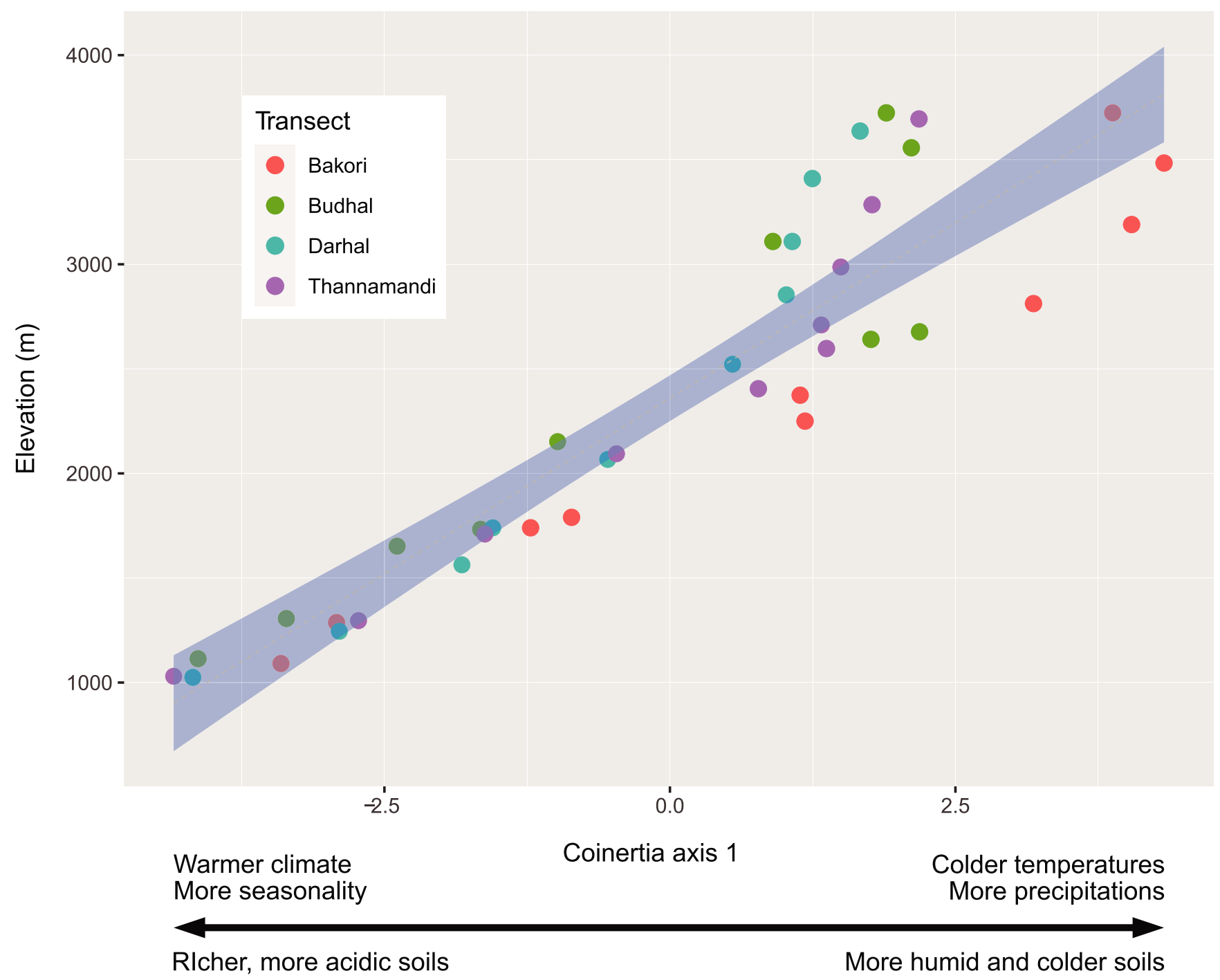

FIGURE 2 Climate and soil properties' covariation along elevation. Gray shading shows best fitting of the linear model with confidence intervals when the correlation is significant $(p<.05)$. Dots are colored for distinguishing the four different elevation transects

\section{RESULTS}

1. Soil-climate covariation along elevation: We found that elevation was correlated with soil moisture, $\mathrm{pH}$, temperature, and conductivity. Particularly, soil temperature $\left(t_{39}=-31.70\right.$, $p$-value $<.001$ ), conductivity $\left(t_{39}=-11.34, p\right.$-value $<.001$ ), and $\mathrm{pH}\left(t_{39}=-2.04, p\right.$-value $\left.=.047\right)$ all decreased with elevation.
From the lowest to the highest elevations, soil temperature decreased in average by $12.6 \pm 0.4$ degrees, conductivity decreased by a factor of $3.86 \pm 1.14 \mathrm{mS} / \mathrm{m}$, and $\mathrm{pH}$ decreased from 6.35 to 6.10. Soil moisture $\left(t_{39}=23.90, p\right.$-value <.001) increased along the elevational gradient and was in the range of $25.69 \pm 7.21$. For climatic conditions, we found that high elevation sites were on average $9.25 \pm 4.8$ degrees colder, 
$16 \%$ more humid, and $10 \%$ less seasonal variation in precipitation than low-elevation sites (Table S2). We also found that climatic and soil properties across sites were significantly correlated (Figure S1, Monte-Carlo test based on 999 replicates, $r=0.71$, simulated $p$-value $=.001$ ). Finally, we found a positive correlation between the first axis of the soil/climate coinertia analysis (as a proxy of soil and climatic variables' correlation) and elevation (Figure 2, Type III ANOVA with Satterthwaite's method, $F_{1,35.01}, p$-value <.001).

2. Across 40 sites, we retrieved 15,091 nematodes per $100 \mathrm{~g}$ of soil, belonging to 47 genera (Table S3). Nematode communities observed along the elevational transects varied considerably in their composition (Figure S2). Low-elevation soils found in forested areas, ranging from altitude $1,000 \mathrm{~m}$ to $2,500 \mathrm{~m}$, were mainly composed of genera like Plectus, Acrobeles, Mesorhabditis, Mylonchulus, Aphelenchus, Alaimus, Wilsonema, and Eudorylaimus, while those found between the range of $2,500 \mathrm{~m}$ and $3,500 \mathrm{~m}$ were composed of genera like Mesodorylaimus, Prodorylaimus, Aphelenchoides, Teratocephalus, Panagrolaimus, Tylencholaimus, Paratylenchus, and Helicotylenchus. However, in the transition zones of elevation transects, various genera coexist, for example, Helicotylenchus and Eudorylaimus, which were found both in lower transects and in the middle transects, whereas genera like Teratocephalus, Panagrolaimus, and Prodorylaimus were found both in mid-elevation transects and in the upper elevation transects at an altitude of 3,500 m a.s.l. Some genera were completely absent in some sites, but present in others. For example, the bacterivore genera Cuticularia, Curviditis, and Rhabditis were not found at high elevations, while Longidorella, Nagelus were not found at low elevations. Furthermore, above 3,500 m a.s.I., nematode communities mostly consisted of few herbivore and omnivore genera like Pratylenchus, Longidorella, Prodorylaimus, and Panagrolaimus. Overall, we observed a general increase in the number of nematodes along the elevational gradient, but the diversity of nematode communities declined at the highest elevations (above 3,500 $\mathrm{m}$ a.s.l.), which mostly consisted of herbivore and omnivore genera (Table 1, Figure 3). Among climatic variables, diurnal temperature range and isothermality were significantly associated with more bacterivores and predators, while seasonality was significantly correlated with more omnivores and herbivores (Figure S3, Table S4). Among soil variables, $\mathrm{pH}$ was negatively associated with fungivores, but positively associated with herbivores, while conductivity and temperature were positively associated with bacterivores, and finally, soil moisture was positively associated with omnivores (Figure S3, and Table S4).

3. We found that indices related to ecosystem properties varied with elevation (Figure S4), with nematode communities being associated with more productive and mature ecosystems found more likely living at low versus high elevation. Specifically, (a) the $\Sigma \mathrm{Ml}$ showed an increase along the elevational gradient (Table 2, Figure 4a), depicting an increase in the relative abundance of persister nematodes when moving up along the elevational gradient, while (b) the El showed a decline with elevation (Table 2, Figure 4b).

\section{4 | DISCUSSION}

Abiotic variation along elevational gradients shapes species diversity patterns, both for above- and belowground organisms, but the generalities of these patterns are still a matter of debate and vary across guilds of taxa (Sundqvist et al., 2013). Here, we studied elevational gradients in soil nematode functional structure in the lesser Himalayan range, and found that variation in nematode communities' functional composition along the elevational gradient was related to a shared structure of climatic and edaphic variables. Second, we found an increase in functional diversity and nematodes' footprints with elevation. Third, functional indices analyses highlighted a more stable ecological successional status and high amplitude of carbon utilization at high-elevation sites, respectively. Below, we expand on these findings, and extrapolate on the relevance of soil nematodes' functional indices for characterizing ecosystem changes along ecological gradients.

\section{1 | Elevation effect on soil nematodes' trophic groups in relation to edaphic and climatic variables}

We analyzed nematode communities' linkages to ecosystem function by studying sites-specific soil and climatic variables along the elevational gradient. First, our results show an increase in soil moisture content along the elevation, which can be attributed to the increase in mean annual climatic precipitation and a decrease in precipitation seasonality. These properties were in turn related to increase in the abundance and diversity of nematodes along the elevation (Li et al., 2020). Indeed, we observed that most trophic groups of nematodes, except the bacterivores, which showed a decline, and the parasites, which showed no variation in abundance along elevation, all increased with elevation. Similarly, it was previously observed that soil nematodes' diversity is higher in cooler, more humid soils (Dong et al., 2017; Kergunteuil, 2016). Such trends might be counterintuitive, as the diversity and abundance of most taxonomic groups studied so far; e.g., plants (Bryant et al., 2008), arthropods (Hodkinson, 2005), or birds (Duclos et al., 2019; Patterson et al., 1998), all show either a steady decline or a bell-shaped relationship with elevation (Brehm et al., 2007; Fernandez-Conradi et al., 2020; Godschalx et al., 2019). This is thought to be the reflection of the climate becoming colder and harsher, and growing seasons becoming shorter at high elevation (Chapin \& Korner, 1995), a pattern that we also observed: a decrease in mean diurnal temperature range, along with an increase in mean precipitation and a decrease in precipitation seasonality with the increasing elevation. Nematodes, in contrast, we observed to increase in abundance and functional (trophic) diversity with elevation. Other studies have shown the ability of nematodes to inhabit the harshest environments, such as the extreme polar regions (Loof, 1971; Yeates, 2010). Accordingly, we might speculate that nematodes can actually thrive more at high elevation, as they display adaptations to extreme low temperatures, such as the ability of supercooling and anhydrobiosis (Pickup, 1990; Pickup \& Rothery, 1991; Wharton, 1995, 1996), while 

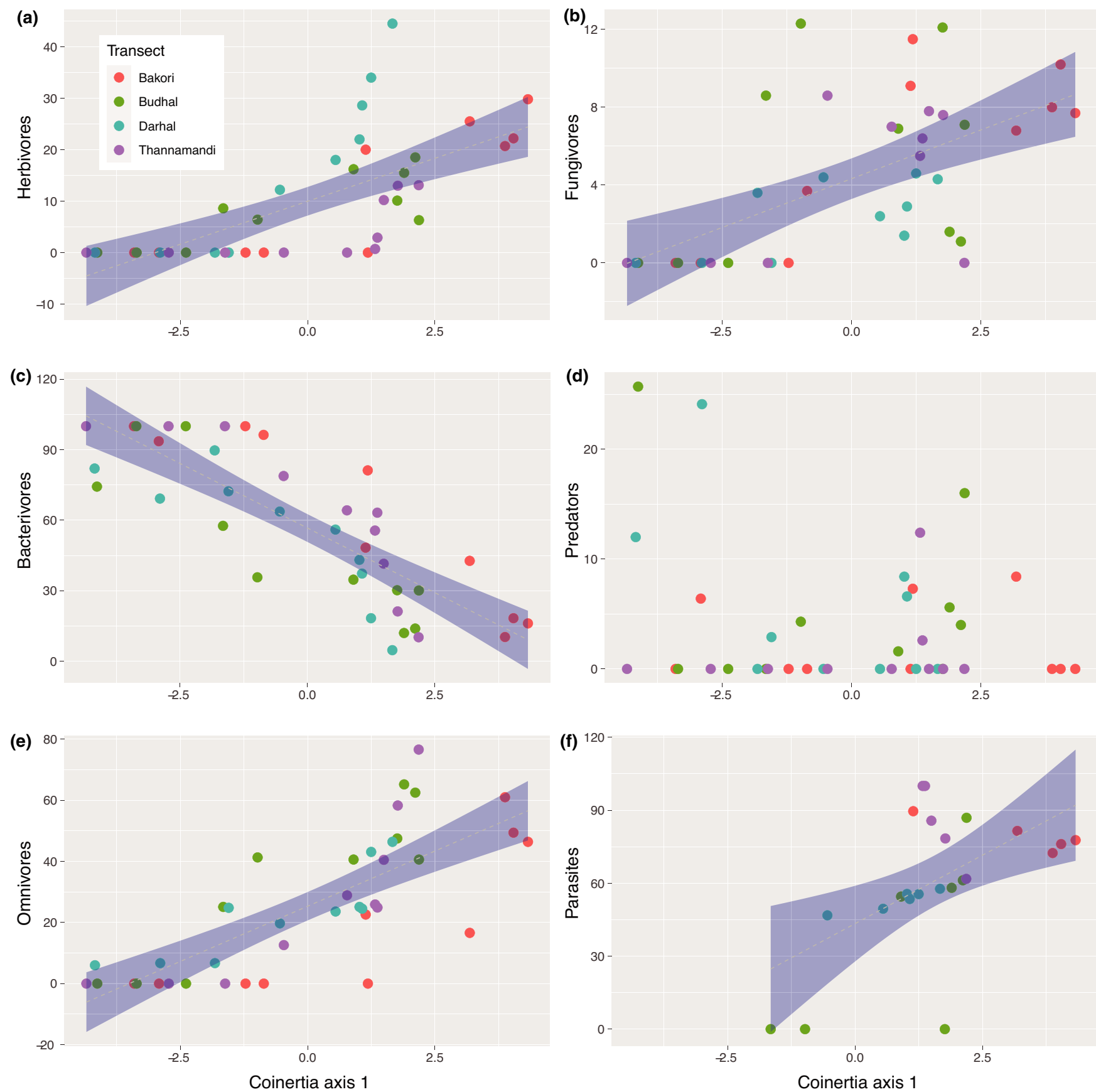

FIGURE 3 Effect of the coupled climate/soil variation along elevation and the abundance of different nematodes' trophic groups. (a) Herbivores, (b) fungivores, (c) bacterivores, (d) predators, (e) omnivores, (f) parasites. Abundances of nematodes represent densities per $100 \mathrm{~g}$ fresh soil. Different colors represent the sampling sites belonging to four mountain transects as shown in Table S1. Gray shading shows best fitting of the linear model with confidence intervals when the correlation is significant $(p<.05)$. Dots are colored for distinguishing the four different elevation transects

on the other hand, they might suffer from desiccation in warmer and drier conditions of low-elevation sites (Procter, 1990).

Along with climatic variables, we also observed that soil conditions varied with elevation, and that they were also correlated with variation in nematodes' trophic groups. This is in line with previous results showing that soil variables are indeed important determinants of the composition of soil nematode communities (Li et al., 2020; Nielsen et al., 2014; Song et al., 2017; Wu et al., 2011). For instance, increased free water availability at high elevation is an important aspect for nematode movement and might thus be a contributing factor for promoting nematode populations in the alpine environment (Landesman et al., 2011). Taken together, we could argue that variation in nematode community composition and diversity along the elevation gradient could be explained by the shared effects of soil and climatic factors, highlighting the crucial role of interaction among multiple ecological factors on soil biodiversity. Nonetheless 


\begin{tabular}{lllllll} 
Indices & SQ & NumDF & DenDF & \multicolumn{2}{c}{$\operatorname{Pr}(>F)$} \\
\hline$\Sigma$-maturity & 24.202 & 1 & 35.441 & 169.38 & $4.60 \mathrm{E}-15$ & $* * *$ \\
Channel & $2,854.3$ & 1 & 37.365 & 9.2445 & 0.0043 & $* *$ \\
\hline Enrichment & $4,548.9$ & 1 & 37.727 & 18.323 & 0.0001231 & $* * *$ \\
MF & 46,968 & 1 & 38 & 36.046 & $5.62 \mathrm{E}-07$ & $* * *$
\end{tabular}

TABLE 2 Type III Analysis of Variance Table with Satterthwaite's method for (1) The $\Sigma M I,(2)$ The enrichment index, (3) The channel index, and (4) The metabolic footprints (MF)

Note: Signif. codes: $00^{(* * *)} 0.001^{(* *)} 0.01^{(*)} 0.05$ ". $0.1^{\prime \prime} 1$.

(a)

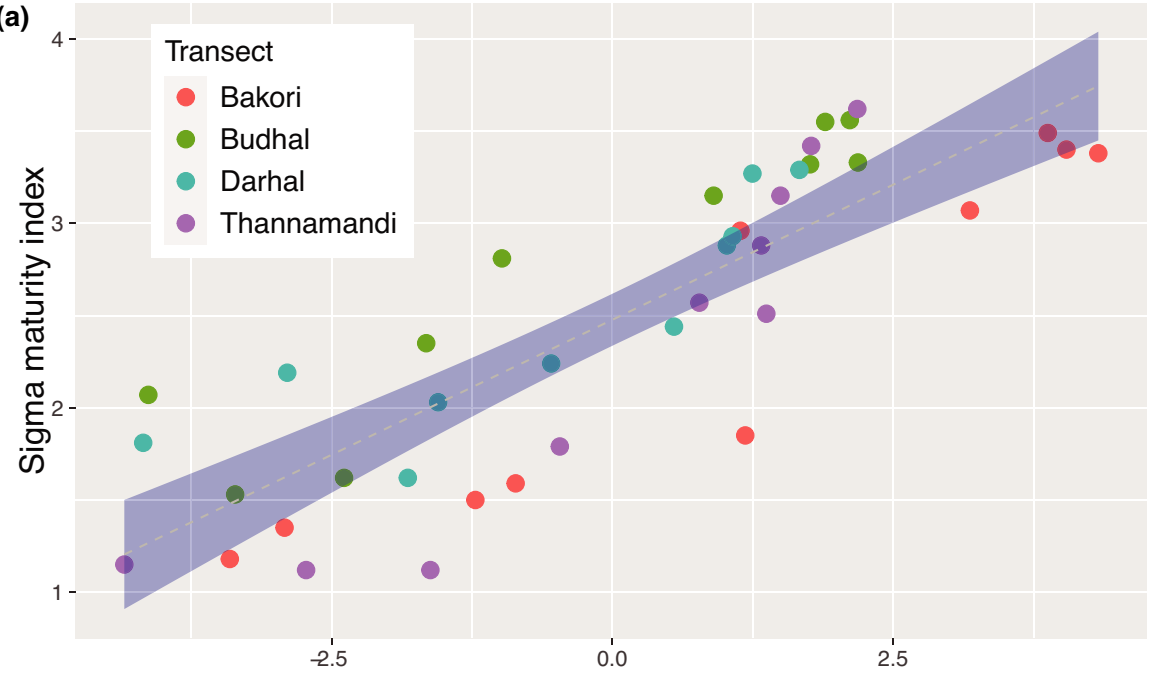

FIGURE 4 Effect of the coupled climate/soil variation along elevation and soil nematode functionality. Shown are linear model regression between the climate/soil coinertia axis 1 (see Figure S1), and (a) the $\Sigma M I$, (b) the Enrichment index. Gray shading shows best fitting of the linear model with confidence intervals when the correlation is significant $(p<.05)$. Dots are colored for distinguishing the four different elevation transects

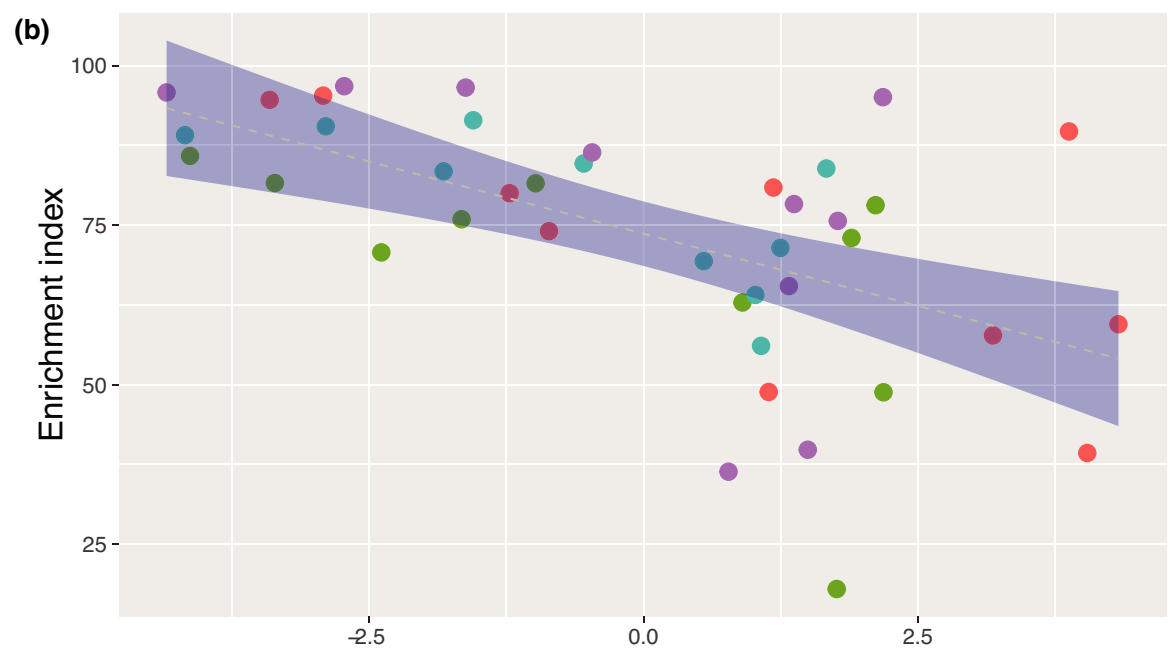

Coinertia axis 1 the climatic and edaphic factors explained only a proportion of the total variation in nematode diversity and composition (from $20 \%$ to $68 \%$ ), suggesting that other potential and indirect explanatory variables, such as the vegetation characteristics or soil microbes, providing the habitat as well as food for nematodes, could also influence soil nematode diversity (Decaëns, 2010; Wardle, 2006). One caveat of our study is that we did not include classic diversity measures (e.g., Shannon, Simpson measures of entropy) of nematode communities along elevation gradients. The principal reason for this omission is that the taxonomic level at which we were working with, mostly using trophic and functional groups, does not allow a sufficient fine taxonomic resolution for these calculations to be any meaningful. Future work that scores soil nematode communities based on precise taxonomy, such as using DNA metabarcoding techniques, or through morphospecies scoring (Dell'Anno et al., 2015; Schenk et al., 2019), will very likely enable better estimates of alpha and beta diversity changes along elevation gradients.

\subsection{Elevational variation in soil nematode functional indices related to ecosystem properties}

While studies of taxonomic variation can inform on biodiversity changes along ecological gradients, the functional characterization of major players in the community, such as nematodes, is necessary to link biodiversity to ecosystem functioning (van den Hoogen et al., 2019, 
2020; Tilman, 2001; Wall \& Lynch, 2000). We here addressed the functional composition of nematodes by studying multiple integrative functional indices, including the $\Sigma \mathrm{MI}$, which increased with elevation. Such patterns was likely driven by an increase in plant parasitic nematodes index (PPI) and stable soil conditions, that is, less disturbed environment (Bongers, 1990) at high elevation. We suspect that the reason for the observed increase in PPI with elevation goes hand in hand with changes in soil moisture, conductivity, and the climatic variables, particularly seasonality, precipitation, and temperature. Such conditions provide convenient environment for soil-dwelling nematodes of larger body size, longer life cycles, that is, 'persistent group' of nematodes. That said, the increase in $\Sigma \mathrm{Ml}$ along the elevational gradient depends on both the free-living and the plant-parasitic nematodes; however, high elevations were mostly inhabited by plant-parasitic and omnivore nematode genera, likely due to their better tolerance to stress conditions (Bongers, 1990). A general decrease in the temperatures can also contribute to the maintenance of nematodes with long life cycles and low reproduction rates, thus, favoring the persister groups at high elevations. Furthermore, at high elevations, a denser root system provides a more suitable environment for herbivore and omnivore nematodes, by providing shelter from various abiotic stress, as well potentially providing enemy-free zones (Kergunteuil, 2016).

Another index portraying the functional structure of nematode communities is the enrichment index (EI), which showed a negative correlation with elevation, although we detected strong variability right above the tree line (Figure 4b). Higher El values indicate resource enrichment, and can be used to classify more undisturbed and more stable habitats (Ferris et al., 2001). Therefore, our findings suggest that across the elevational transects, soil resources are richer at lower than at higher altitudes. This might be explained by the slower erosion processes, and faster decomposition rates at lower elevations (Murphy et al., 1998), which lead to higher concentrations of nutrients in low-elevation soils. Plant adaptations to high elevations include long leaf life span and slow growth. Moreover, high-elevation soil organic matter decomposition is slow, likely due to thermal inhibition of the metabolic machinery (Pellissier \& Rasmann, 2018). All together, these patterns result in decreased mineralization processes and decreased soil fertility (e.g., as shown by a decrease in soil conductivity at high elevation) (Wardle, 2006), and thus likely favoring enhanced fungal-based energy flow at higher elevation (Wardle \& Yeates, 1993; Zhao \& Neher, 2014). Therefore, the El can be used to extrapolate at which elevation the soil was sampled, as well as the quality of the soil in relation to productivity (Tsiafouli et al., 2017).

\section{5 | CONCLUSIONS}

Changes in ecological factors like soil quality (Bongers, 1990), soil characteristics (de Goede \& Bongers, 1994), habitat stability (Wasilewska, 1994), and climate (Crawford et al., 1991; Papatheodorou et al., 2004; Ruess et al., 1999; Sohlenius \& Bostrom, 1999) strongly reflect on soil nematode functional composition, and therefore, it has been predicted that different ecosystems or habitats should sustain different communities of soil nematodes. Accordingly, we here showed that along elevation gradients, soil nematodes are particularly good bioindicators of local ecosystem properties (Overgaard, 1949; Procter, 1984; Yeates, 2003). Particularly, we showed that alpine ecosystems sustain a wider range of functional and taxonomic diversity than their respective low-elevation sites. These results are in line with previous findings obtained along elevation gradients in the Alps (Kergunteuil, 2016), or across broad latitudinal gradients (van den Hoogen et al., 2019), and future work should focus on extending similar research to study the stability of such patterns across sites and years. Indeed, mountain ranges are unusually biodiverse, with copious accumulations of endemic species, which is the reflection of high variation in hydrology, in meteorology, as well as in ecological and evolutionary processes (Hoschitz \& Kaufmann, 2004; Rahbek et al., 2019). Accordingly, mountains play an important role in sustaining Earth's biodiversity and ecosystem functioning (Körner, 2004). Soil nematodes contribute tremendously to such diversity, in terms of both taxonomic and functional diversity. Therefore, a better understating of the causes that generate nematodes biodiversity can inform on the impact of climate change and land-use change on ecosystem functioning worldwide.

\section{ACKNOWLEDGMENTS}

We thank Dr Mohd Saleem for providing assistance during field collection. This work was supported by the Council of Scientific and Industrial Research (CSIR, India, File number 09/1172(0002)/EMR2018), which granted research fellowship to $Y K$, and by a Swiss National Science Foundation grant (31003A_159869) to SR.

\section{CONFLICT OF INTEREST}

None to declare.

\section{AUTHOR CONTRIBUTIONS}

Yasmeen Kouser: Conceptualization (equal); data curation (equal); formal analysis (equal); funding acquisition (supporting); investigation (lead); methodology (lead); project administration (equal); resources (lead); software (equal); supervision (supporting); validation (equal); visualization (equal); writing-original draft (equal); writing-review \& editing (equal). Ali Asghar Shah: Conceptualization (lead); data curation (equal); formal analysis (supporting); funding acquisition (equal); investigation (equal); methodology (equal); project administration (lead); resources (equal); software (equal); supervision (lead); validation (equal); visualization (equal); writing-original draft (equal); writing-review \& editing (equal). Sergio Rasmann: Conceptualization (equal); data curation (equal); formal analysis (lead); funding acquisition (equal); investigation (equal); methodology (equal); project administration (equal); resources (equal); software (equal); supervision (lead); validation (equal); visualization (equal); writing-original draft (lead); writing-review \& editing (lead).

\section{DATA AVAILABILITY STATEMENT}

Data underlying this article can be accessed on Dryad Digital Repository at https://doi.org/10.5061/dryad.v41ns1rx0, and used under the Creative Commons Attribution license. 


\section{ORCID}

Sergio Rasmann (iD https://orcid.org/0000-0002-3120-6226

\section{REFERENCES}

Andrén, O., Bengtsson, J., \& Clarholm, M. (1995). Biodiversity and species redundancy among litter decomposers. In H. P. Collins, G. P. Robertson, \& M. J. Klug (Eds.), The significance and regulation of soil biodiversity: Proceedings of the international symposium on soil biodiversity, held at Michigan State University, East Lansing, May 3-6, 1993 (pp. 141-151). Developments in Plant and Soil Sciences. Springer Netherlands. https://doi.org/10.1007/978-94-011-0479-1_12

Bach, E., Ramirez, K., Fraser, T. D., \& Wall, D. (2020). Soil biodiversity integrates solutions for a sustainable future. Sustainability, 12, 2662. https://doi.org/10.3390/su12072662

Bardgett, R. D., \& van der Putten, W. H. (2014). Belowground biodiversity and ecosystem functioning. Nature, 515, 505-511. https://doi. org/10.1038/nature13855

Barker, K. R. (1985). Nematode extraction and bioassays.

Bates, D., Mächler, M., Bolker, B., \& Walker, S. (2015). Fitting linear mixed-effects models using Ime4. Journal of Statistical Software, 67, 1-48. https://doi.org/10.18637/jss.v067.i01

Berkelmans, R., Ferris, H., Tenuta, M., \& van Bruggen, A. (2003). Effects of long-term crop management on nematode trophic levels other than plant feeders disappear after 1 year of disruptive soil management. Applied Soil Ecology, 23, 223-235. https://doi.org/10.1016/ S0929-1393(03)00047-7

Bongers, T. (1990). The maturity index: An ecological measure of environmental disturbance based on nematode species composition. Oecologia, 83, 14-19. https://doi.org/10.1007/BF00324627

Bongers, T., \& Bongers, M. (1998). Functional diversity of nematodes. Applied Soil Ecology, 10, 239-251. https://doi.org/10.1016/S0929 -1393(98)00123-1

Bongers, T., \& Ferris, H. (1999). Nematode community structure as a bioindicator in environmental monitoring. Trends in Ecology \& Evolution, 14, 224-228. https://doi.org/10.1016/S0169-5347(98)01583-3

Boström, S., \& Sohlenius, B. (1986). Short-term dynamics of nematode communities in arable soil Influence of a perennial and an annual cropping system. Pedobiologica Jena, 29, 345-357.

Brehm, G., Colwell, R., \& Kluge, J. (2007). The role of environment and mid-domain effect on moth species along a tropical elevational gradient. Global Ecology and Biogeography, 16, 205-219. https://doi. org/10.1111/j.1466-822x.2006.00281.x

Brinkman, E. P., Duyts, H., \& van der Putten, W. H. (2008). Interactions between root-feeding nematodes depend on plant species identity. Soil Biology \& Biochemistry, 40, 2186-2193. https://doi.org/10.1016/j. soilbio.2008.01.023

Brussaard, L. (1997). Biodiversity and ecosystem functioning in soil. Ambio, 26, 563-570.

Bryant, J. A., Lamanna, C., Morlon, H., Kerkhoff, A. J., Enquist, B. J., \& Green, J. L. (2008). Microbes on mountainsides: Contrasting elevational patterns of bacterial and plant diversity. Proceedings of the National Academy of Sciences, 105, 11505-11511. https://doi. org/10.1073/pnas.0801920105

Chapin, F. S., \& Korner, C. (1995). Arctic and alpine biodiversity: Patterns, causes and ecosystem consequences. Springer-Verlag.

Chen, D., Cheng, J., Chu, P., Hu, S., Xie, Y., Tuvshintogtokh, I., \& Bai, Y. (2015). Regional-scale patterns of soil microbes and nematodes across grasslands on the Mongolian plateau: Relationships with climate, soil, and plants. Ecography, 38, 622-631. https://doi. org/10.1111/ecog.01226

Collins, H. P., Robertson, G. P., \& Klug, M. J. (1995). Significance and regulation of soil biodiversity. Kluwer Academic. https://agris.fao.org/agris -search/search.do?recordID=US201300289738

Cook, R., Evans, D. R., Williams, T. A., \& Mizen, K. A. (1992). The effect of stem nematode on establishment and early yields of white clover.
The Annals of Applied Biology, 120, 83-94. https://doi.org/10.1111/ j.1744-7348.1992.tb03406.x

Crawford, J. W., Harris, J. A., Ritz, K., \& Young, I. M. (2005). Towards an evolutionary ecology of life in soil. Trends in Ecology \& Evolution, 20, 81-87. https://doi.org/10.1016/j.tree.2004.11.014

Crawford, J. W., Neilson, R., \& Boag, B. (1991). The effect of potential climatic changes on the geographical distribution of the plant-parasitic nematodes Xiphinema and Longidor us in Europe. Nematologica, 37, 312-323. https://doi.org/10.1163/187529291X00312

De Deyn, G. B., Raaijmakers, C. E., van Ruijven, J., Berendse, F., \& van der Putten, W. H. (2004). Plant species identity and diversity effects on different trophic levels of nematodes in the soil food web. Oikos, 106, 576-586. https://doi.org/10.1111/j.0030-1299.2004.13265.x

De Deyn, G. B., Raaijmakers, C. E., Zoomer, H. R., Berg, M. P., de Ruiter, P. C., Verhoef, H. A., Bezemer, T. M., \& van der Putten, W. H. (2003). Soil invertebrate fauna enhances grassland succession and diversity. Nature, 422, 711-713. https://doi.org/10.1038/nature01548

de Goede, R. G. M., \& Bongers, T. (1994). Nematode community structure in relation to soil and vegetation characteristics. Applied Soil Ecology, 1, 29-44. https://doi.org/10.1016/0929-1393(94)90021-3

De La Peña, E., Echeverría, S. R., Van Der Putten, W. H., Freitas, H., \& Moens, M. (2006). Mechanism of control of root-feeding nematodes by mycorrhizal fungi in the dune grass Ammophila arenaria. New Phytologist, 169, 829-840. https://doi.org/10.1111/j.1469-8137. 2005.01602.x

de Ruiter, P. C., Neutel, A.-M., \& Moore, J. C. (1998). Biodiversity in soil ecosystems: The role of energy flow and community stability. Applied Soil Ecology, 10, 217-228. https://doi.org/10.1016/S0929 -1393(98)00121-8

Decaëns, T. (2008). Priorities for conservation of soil animals. CAB Reviews: Perspectives in Agriculture, Veterinary Science, Nutrition and Natural Resources, 3, 1-18. https://doi.org/10.1079/PAVSNNR200 83014

Decaëns, T. (2010). Macroecological patterns in soil communities. Global Ecology and Biogeography, 19, 287-302. https://doi. org/10.1111/j.1466-8238.2009.00517.x

Decaëns, T., Jiménez, J. J., Gioia, C., Measey, G. J., \& Lavelle, P. (2006). The values of soil animals for conservation biology. European Journal of Soil Biology, 42, S23-S38. https://doi.org/10.1016/j. ejsobi.2006.07.001

Dell'Anno, A., Carugati, L., Corinaldesi, C., Riccioni, G., \& Danovaro, R. (2015). Unveiling the biodiversity of deep-sea nematodes through metabarcoding: Are we ready to bypass the classical taxonomy? PLoS One, 10, e0144928. https://doi.org/10.1371/journal.pone.0144928

Dinoor, A., \& Eshed, N. (2003). The role and importance of pathogens in natural plant communities. Annual Review of Phytopathology, 22, 443-466. https://doi.org/10.1146/annurev.py.22.090184.002303

Djigal, D., Brauman, A., Diop, T. A., Chotte, J. L., \& Villenave, C. (2004). Influence of bacterial-feeding nematodes (Cephalobidae) on soil microbial communities during maize growth. Soil Biology \& Biochemistry, 36, 323-331. https://doi.org/10.1016/j.soilbio.2003.10.007

Dong, K. E., Moroenyane, I., Tripathi, B., Kerfahi, D., Takahashi, K., Yamamoto, N., An, C., Cho, H., \& Adams, J. (2017). Soil nematodes show a mid-elevation diversity maximum and elevational zonation on Mt. Norikura, Japan. Scientific Reports, 7, 3028. https://doi. org/10.1038/s41598-017-03655-3

Dray, S., Chessel, D., \& Thioulouse, J. (2003). Co-Inertia analysis and the linking of ecological data tables. Ecology, 84, 3078-3089. https://doi. org/10.1890/03-0178

Dray, S., \& Dufour, A.-B. (2007). The ade4 package: Implementing the duality diagram for ecologists. Journal of Statistical Software, 22, 120. https://doi.org/10.18637/jss.v022.i04

Duclos, T. R., DeLuca, W. V., \& King, D. I. (2019). Direct and indirect effects of climate on bird abundance along elevation gradients in the Northern Appalachian mountains. Diversity and Distributions, 25, 1670-1683. https://doi.org/10.1111/ddi.12968 
Fernandez-Conradi, P., Mocellin, L., Desfossez, E., \& Rasmann, S. (2020). Seasonal changes in arthropod diversity patterns along an Alpine elevation gradient. Ecological Entomology, 45, 1035-1043. https://doi. org/10.1111/een.12881

Ferris, H. (2010). Form and function: Metabolic footprints of nematodes in the soil food web. European Journal of Soil Biology, 46, 97-104. https://doi.org/10.1016/j.ejsobi.2010.01.003

Ferris, H., \& Bongers, T. (2009). Indices developed specifically for analysis of nematode assemblages. In M. J. Wilson, \& T. Kakouli-Duarte (Eds.), Nematodes as environmental indicators (pp. 124-145). CABI. https://doi.org/10.1079/9781845933852.0124

Ferris, H., Bongers, T., \& de Goede, R. G. M. (2001). A framework for soil food web diagnostics: Extension of the nematode faunal analysis concept. Applied Soil Ecology, 18, 13-29. https://doi.org/10.1016/ S0929-1393(01)00152-4

Fitter, A. H., Gilligan, C. A., Hollingworth, K., Kleczkowski, A., Twyman, R. M., \& Pitchford, J. W. (2005). Biodiversity and ecosystem function in soil. Functional Ecology, 19, 369-377. https://doi. org/10.1111/j.0269-8463.2005.00969.x

Freckman, D. W., \& Ettema, C. H. (1993). Assessing nematode communities in agroecosystems of varying human intervention. Agriculture, Ecosystems \& Environment, 45, 239-261. https://doi. org/10.1016/0167-8809(93)90074-Y

Freckman, D. W., \& Virginia, R. A. (1989). Plant-feeding nematodes in deep-rooting desert ecosystems. Ecology, 70, 1665-1678. https:// doi.org/10.2307/1938101

Godschalx, A. L., Rodríguez-Castañeda, G., \& Rasmann, S. (2019). Contribution of different predator guilds to tritrophic interactions along ecological clines. Current Opinion in Insect Science, 32, 104-109. https://doi.org/10.1016/j.cois.2019.01.002

Hodda, M. (2011). Phylum Nematoda Cobb 1932. In: Z.-Q. Zhang (Ed.), Animal biodiversity: An outline of higher-level classification and survey of taxonomic richness. Zootaxa (Vol. 3148, pp. 63-95). https://doi. org/10.11646/zootaxa.3148.1.11

Hodda, M. E., Peters, L., \& Traunspurger, W. (2009). Nematode diversity in terrestrial, freshwater aquatic and marine systems.

Hodkinson, I. D. (2005). Terrestrial insects along elevation gradients: Species and community responses to altitude. Biological Reviews, 80, 489. https://doi.org/10.1017/S1464793105006767

Hoschitz, M., \& Kaufmann, R. (2004). Soil nematode communities of Alpine summits-site differentiation and microclimatic influences. Pedobiologia, 48, 313-320. https://doi.org/10.1016/j.pedobi.2004.03.004

Hugot, J.-P., Baujard, P., \& Morand, S. (2001). Biodiversity in helminths and nematodes as a field of study: An overview. Nematology, 3, 199208. https://doi.org/10.1163/156854101750413270

Hunt, H., \& Wall, D. (2002). Modeling the effects of loss of soil biodiversity on ecosystem function. Global Change Biology, 8, 33-50. https:// doi.org/10.1046/j.1365-2486.2002.00425.x

Karger, D. N., Conrad, O., Böhner, J., Kawohl, T., Kreft, H., Soria-Auza, R. W., Zimmermann, N. E., Linder, H. P., \& Kessler, M. (2017). Climatologies at high resolution for the earth's land surface areas. Scientific Data, 4(1), 170122. https://doi.org/10.1038/sdata.2017.122

Kergunteuil, A., Campos-Herrera, R., Sánchez-Moreno, S., Vittoz, P., \& Rasmann, S. (2016). The abundance, diversity, and metabolic footprint of soil nematodes is highest in high elevation Alpine grasslands. Frontiers in Ecology and Evolution, 4, 12. https://doi.org/10.3389/ fevo.2016.00084

Körner, C. (2004). Mountain biodiversity, its causes and function. AMBIO: A Journal of the Human Environment, 33, 11-17. https://doi. org/10.1007/0044-7447-33.sp13.11

Körner, C. (2007). The use of 'altitude' in ecological research. Trends in Ecology \& Evolution, 22, 569-574. https://doi.org/10.1016/j. tree.2007.09.006

Krumins, J. A., van Oevelen, D., Bezemer, T. M., De Deyn, G. B., Hol, W. H. G., van Donk, E., de Boer, W., de Ruiter, P. C., Middelburg, J. J., Monroy, F., Soetaert, K., Thébault, E., van de Koppel, J., van Veen,
J. A., Viketoft, M., \& van der Putten, W. H. (2013). Soil and freshwater and marine sediment food webs: Their structure and function. BioScience, 63, 35-42. https://doi.org/10.1525/bio.2013.63.1.8

Kuhn, M., Wing, J., Weston, S., Williams, A., Keefer, C., \& Engelhardt, A. (2020). caret: Classification and regression training. https://CRAN.Rproject.org/package $=$ caret

Landesman, W. J., Treonis, A. M., \& Dighton, J. (2011). Effects of a oneyear rainfall manipulation on soil nematode abundances and community composition. Pedobiologia, 54, 87-91. https://doi.org/10.1016/j. pedobi.2010.10.002

Li, X., Chen, X., Zhu, H., Ren, Z., Jiao, J., Hu, F., \& Liu, M. (2020). Effects of historical legacies on soil nematode communities are mediated by contemporary environmental conditions. Ecology and Evolution, 10, 6732-6740. https://doi.org/10.1002/ece3.6406

Liu, T., Chen, X., Hu, F., Ran, W., Shen, Q., Li, H., \& Whalen, J. K. (2016). Carbon-rich organic fertilizers to increase soil biodiversity: Evidence from a meta-analysis of nematode communities. Agriculture, Ecosystems \& Environment, 232, 199-207. https://doi.org/10.1016/j. agee.2016.07.015

Loof, P. A. A. (1971). Freeliving and plant parasitic nematodes from Spitzbergen, collected by Mr. H. van Rossen. Veenman. https://libra ry.wur.nl/WebQuery/wurpubs/469238

Murphy, K. L., Klopatek, J. M., \& Klopatek, C. C. (1998). The effects of litter quality and climate on decomposition along an elevational gradient. Ecological Applications, 8, 1061-1071. https://doi. org $/ 10.2307 / 2640961$

Nielsen, U. N., Ayres, E., Wall, D. H., Li, G., Bardgett, R. D., Wu, T., \& Garey, J. R. (2014). Global-scale patterns of assemblage structure of soil nematodes in relation to climate and ecosystem properties: Globalscale patterns of soil nematode assemblage structure. Global Ecology and Biogeography, 23, 968-978. https://doi.org/10.1111/geb.12177

Oksanen, J., Blanchet, F. G., Kindt, R., Legendre, P., Minchin, P. R., \& O'Hara, R. B. (2013). vegan: Community ecology package. http:// vegan.r-forge.r-project.org/

Overgaard, N. (1949). Studies on the soil microfauna. 11 The soil inhabiting nematodes. Natura Jutlandica, 2, 287-289.

Papatheodorou, E. M., Argyropoulou, M., \& Stamou, G. P. (2004). The effects of large- and small-scale differences in soil temperature and moisture on bacterial functional diversity and the community of bacterivorous nematodes. Applied Soil Ecology, 25, 37-49. https://doi. org/10.1016/S0929-1393(03)00100-8

Patterson, B. D., Stotz, D. F., Solari, S., Fitzpatrick, J. W., \& Pacheco, V. (1998). Contrasting patterns of elevational zonation for birds and mammals in the Andes of southeastern Peru. Journal of Biogeography, 25, 593-607. https://doi.org/10.1046/j.1365-2699.1998.2530593.x

Pellissier, L., \& Rasmann, S. (2018). The functional decoupling of processes in alpine ecosystems under climate change. Current Opinion in Insect Science, 29, 126-132. https://doi.org/10.1016/j.cois.2018.07.005

Pickup, J. (1990). Strategies of cold-hardiness in three species of Antarctic dorylaimid nematodes. Journal of Comparative Physiology B, 160, 167-173. https://doi.org/10.1007/BF00300949

Pickup, J., \& Rothery, P. (1991). Water-loss and anhydrobiotic survival in nematodes of Antarctic Fellfields. Oikos, 61, 379-388. https://doi. org $/ 10.2307 / 3545245$

Procter, D. L. C. (1984). Towards a biogeography of free-living soil nematodes. I. Changing species richness, diversity and densities with changing latitude. Journal of Biogeography, 11, 103-117. https://doi. org/10.2307/2844684

Procter, D. L. (1990). Global overview of the functional roles of soil-living nematodes in terrestrial communities and ecosystems. Journal of Nematology, 22, 1-7.

Quist, C. W., Gort, G., Mooijman, P., Brus, D. J., van den Elsen, S., Kostenko, O., Vervoort, M., Bakker, J., van der Putten, W. H., \& Helder, J. (2019). Spatial distribution of soil nematodes relates to soil organic matter and life strategy. Soil Biology \& Biochemistry, 136, 107542. https://doi.org/10.1016/j.soilbio.2019.107542 
R Development Core Team. (2020). R: A language and environment for statistical computing. R Foundation for Statistical Computing. Vienna, Austria.

Rahbek, C., Borregaard, M. K., Antonelli, A., Colwell, R. K., Holt, B. G., \& Nogues-Bravo, D. (2019). Building mountain biodiversity: Geological and evolutionary processes

Ritz, K., \& Trudgill, D. L. (1999). Utility of nematode community analysis as an integrated measure of the functional state of soils: Perspectives and challenges. Plant and Soil, 212, 1-11.

Rodriguez-Iturbe, I., D'Odorico, P., Porporato, A., \& Ridolfi, L. (1999). On the spatial and temporal links between vegetation, climate, and soil moisture. Water Resources Research, 35, 3709-3722. https://doi. org/10.1029/1999WR900255

Ruess, L., Michelsen, A., \& Jonasson, S. (1999). Simulated climate change in subarctic soils: Responses in nematode species composition and dominance structure. Nematology, 1, 513-526. https://doi. org/10.1163/156854199508513

Šalamún, P., Kucanová, E., Brázová, T., Miklisová, D., Renčo, M., \& Hanzelová, V. (2014). Diversity and food web structure of nematode communities under high soil salinity and alkaline $\mathrm{pH}$. Ecotoxicology, 23, 1367-1376. https://doi.org/10.1007/s10646-014-1278-7

Schenk, J., Geisen, S., Kleinbölting, N., \& Traunspurger, W. (2019). Metabarcoding data allow for reliable biomass estimates in the most abundant animals on earth. Metabarcoding Metagenomics, 3, e46704. https://doi.org/10.3897/mbmg.3.46704

Sochová, I., Hofman, J., \& Holoubek, I. (2006). Using nematodes in soil ecotoxicology. Environment International, 32, 374-383. https://doi. org/10.1016/j.envint.2005.08.031

Sohlenius, B., \& Bostrom, S. (1999). Effects of global warming on nematode diversity in a Swedish tundra soil - A soil transplantation experiment Nematology, 1, 695-709. https://doi.org/10.1163/156854199508720

Son, J. A., \& Moon, Y.-S. (2013). Efficiency of the Baermann funnel technique as revealed by direct counts of pine wood nematodes in pine tissue. Nematology, 15, 125-127. https://doi.org/10.1163/15685 411-00002690

Song, D., Pan, K., Tariq, A., Sun, F., Li, Z., Sun, X., Zhang, L., Olusanya, O. A., \& Wu, X. (2017). Large-scale patterns of distribution and diversity of terrestrial nematodes. Applied Soil Ecology, 114, 161-169. https:// doi.org/10.1016/j.apsoil.2017.02.013

Sundqvist, M. K., Sanders, N. J., \& Wardle, D. A. (2013). Community and ecosystem responses to elevational gradients: Processes, mechanisms, and insights for global change. Annual Review of Ecology Evolution and Systematics, 44, 261-280. https://doi.org/10.1146/ annurev-ecolsys-110512-135750

Tilman, D. (2001). Functional Diversity. In S. A. Levin (Ed.), Encyclopedia of biodiversity (pp. 109-120). Elsevier. https://doi.org/10.1016/B012-226865-2/00132-2

Tsiafouli, M. A., Bhusal, D. R., \& Sgardelis, S. P. (2017). Nematode community indices for microhabitat type and large scale landscape properties. Ecological Indicators, 73, 472-479. https://doi.org/10.1016/j. ecolind.2016.10.004

van den Hoogen, J., Geisen, S., Crowther, T., Mullin, P., \& Co-authors, M. (2020). A global database of soil nematode abundance and functional group composition.

van den Hoogen, J., Geisen, S., Routh, D., Ferris, H., Traunspurger, W., Wardle, D. A., de Goede, R. G. M., Adams, B. J., Ahmad, W., Andriuzzi, W. S., Bardgett, R. D., Bonkowski, M., Campos-Herrera, R., Cares, J. E., Caruso, T., de Brito Caixeta, L., Chen, X., Costa, S. R., Creamer, R., ... Crowther, T. W. (2019). Soil nematode abundance and functional group composition at a global scale. Nature, 572, 194-198. https:// doi.org/10.1038/s41586-019-1418-6

Viglierchio, D., \& Schmitt, R. V. (1983). On the methodology of nematode extraction from field samples: Baermann funnel modifications. Journal of Nematology, 15, 438.
Wall, D., \& Lynch, J. (2000). Soil biodiversity and ecosystem functioning (pp. 283-290). https://doi.org/10.1007/978-3-662-04033-1_24

Wardle, D. A. (2006). The influence of biotic interactions on soil biodiversity. Ecology Letters, 9, 870-886. https://doi. org/10.1111/j.1461-0248.2006.00931.x

Wardle, D. A., \& Yeates, G. W. (1993). The dual importance of competition and predation as regulatory forces in terrestrial ecosystems: Evidence from decomposer food-webs. Oecologia, 93, 303-306. https://doi.org/10.1007/BF00317685

Wasilewska, L. (1994). The effect of age of meadows on succession and diversity in soil nematode communities.

Wharton, D. A. (1995). Cold tolerance strategies in nematodes. Biological Reviews, 70, 161-185. https://doi.org/10.1111/j.1469-185X.1995. tb01442.x

Wharton, D. (1996). Water loss and morphological changes during desiccation of the anhydrobiotic nematode Ditylenchus dipsaci. Journal of Experimental Biology, 199, 1085-1093. https://doi.org/10.1242/ jeb.199.5.1085

Wilschut, R. A., Geisen, S., Martens, H., Kostenko, O., Hollander, M., Hooven, F. C., Weser, C., Snoek, L. B., Bloem, J., Caković, D., Čelik, T., Koorem, K., Krigas, N., Manrubia, M., Ramirez, K. S., Tsiafouli, M. A., Vreš, B., \& Putten, W. H. (2019). Latitudinal variation in soil nematode communities under climate warming-related range-expanding and native plants. Global Change Biology, 25, 2714-2726. https://doi. org/10.1111/gcb.14657

Wilson, M. J., \& Kakouli-Duarte, T. (2009). Nematodes as environmental indicators. $\mathrm{CABI}$

Wu, T., Ayres, E., Bardgett, R. D., Wall, D. H., \& Garey, J. R. (2011). Molecular study of worldwide distribution and diversity of soil animals. Proceedings of the National Academy of Sciences of the United States of America, 108, 17720-17725. https://doi.org/10.1073/ pnas. 1103824108

Yeates, G. W. (2003). Nematodes as soil indicators: Functional and biodiversity aspects. Biology and Fertility of Soils, 37, 199-210. https://doi. org/10.1007/s00374-003-0586-5

Yeates, G. W. (2010). Nematodes in ecological webs. In Encyclopedia of life sciences. John Wiley \& Sons, Ltd. https://doi.org/10.1002/97804 70015902.a0021913

Yeates, G. W., Bongers, T., De Goede, R. G., Freckman, D. W., \& Georgieva, S. S. (1993). Feeding habits in soil nematode families and genera-an outline for soil ecologists. Journal of Nematology, 25, 315-331.

Zhao, J., \& Neher, D. A. (2014). Soil energy pathways of different ecosystems using nematode trophic group analysis: A meta analysis. Nematology, 16, 379-385. https://doi.org/10.1163/15685 411-00002771

Zhao, J., Zhao, C., Wan, S., Wang, X., Zhou, L., \& Fu, S. (2015). Soil nematode assemblages in an acid soil as affected by lime application. Nematology, 17, 179-191. https://doi.org/10.1163/15685 411-00002860

\section{SUPPORTING INFORMATION}

Additional supporting information may be found online in the Supporting Information section.

How to cite this article: Kouser, Y., Shah, A. A., \& Rasmann, S. (2021). The functional role and diversity of soil nematodes are stronger at high elevation in the lesser Himalayan Mountain ranges. Ecology and Evolution, 11, 13793-13804. https://doi. org/10.1002/ece3.8061 